\title{
Issues of Carbothermic Synthesis of Submicron and Nanostructured Boron Carbide (A Review)
}

\section{ALEXEY VYACHESLAVOVICH ANTIPOV ${ }^{1}$, OLGA MIKHAYLOVNA ANTIPOVA², ALYONA IGOREVNA WOZNIAK ${ }^{1}$, VITALY SERGEYEVICH IVANOV', OLGA ANATOLEVNA ZHDANOVICH ${ }^{1}$ and ANTON SERGEYEVICH YEGOROV ${ }^{1 *}$}

\author{
${ }^{1}$ Federal State Unitary Enterprise «State Scientific Research Institute of Chemical Reagents and High \\ Purity Chemical Substances»(FSUE "IREA”), 107076, Bogorodskyval, 3. Moscow. Russia. \\ ${ }^{2}$ Chemistry Department, M.V. LomonosovMoscow State University, 119991, Leninskiye Gory 1-3. \\ Moscow. Russia. \\ ${ }^{*}$ Corresponding author E-mail: egorov@irea.org.ru \\ http://dx.doi.org/10.13005/ojc/320601
}

(Received: October 15, 2016; Accepted: November 29, 2016)

\begin{abstract}
This review shows the important role of nanoscale and submicron boron carbide B4C for modern science and technology. Various procedures of the carbothermic synthesis of nanoscale and submicron forms of boron carbide are reviewed and compared. The paper shows the variety of possible forms and morphology of the products. Particular attention is paid to the influence of the synthesis method on the content of residual free carbon in the product.
\end{abstract}

Keywords: Boron carbide, nanopowder, carbothermic synthesis, sol-gel.

\section{INTRODUCTION}

Boron carbide takes a special place among the superhard ceramic materials. This substance has a set of unique properties such as extremely high hardness, wear resistance, thermal, chemical and radiation stability. Due to the content of the isotope, $10 \mathrm{~B}$ boron carbide is a highly efficient absorber of neutrons in the nuclear industry devices. Methods for producing coarse-grained boron carbide have been studied and implemented commercially long time ago. Coarse-grained boron carbide is cheap enough. However, production of high-quality high-density and high-strength ceramics made of such boron carbide is a rather difficult process, due to the high temperature of its melting point and low sinterability. One method to improve the performance characteristics of ceramics is to use nanoscale powders as starting materials. Also, composites with unique properties can be produced from the nanopowders, the creation of which is fundamentally impossible on the basis of coarse-grained analogues ${ }^{1,2}$. 
Unfortunately, currently, despite the rapid progress in this field, the available scientific research results do not allow to create enough effective production of boron carbide nanopowder of high purity (see Fig.1). The prices for it are quite high (around \$ 800 per $100 \mathrm{~g})^{3}$, and scare away potential customers. Therefore, the problem of search more rational and accessible methods of synthesis of $\mathrm{B}_{4} \mathrm{C}$ nanopowderis still relevant.

Methods available for boron carbide synthesis

From a technical point of view, the synthesis of carbides nanopowders (regardless of the method used) is one of the most difficult, as compared with the synthesis of oxides nanopowders or pure elements. Currently, scientists focus mostly on such approaches as:

- $\quad$ Carbothermic synthesis based highlydispersed forms of carbon or on precursors obtained by the "sol-gel" method" 4-21;

- $\quad$ Metallothermic synthesis (preferably using sodium or magnesium as a reducing agent) ${ }^{22-25}$;

- $\quad$ Synthesis by condensation of nanoparticles in the plasma jet ${ }^{26-28}$;

- Chemical vapor deposition (CVD) synthesis ${ }^{29,30}$;

- Mechanochemical production ${ }^{31-33}$.

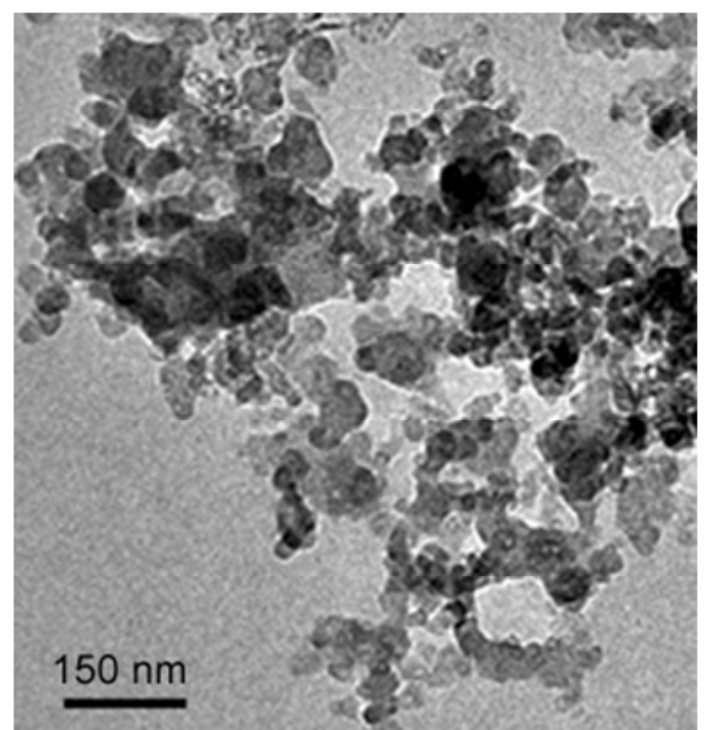

Fig.1:Commercially available Boron Carbide Nanoparticles/Nanopowder (B4C, 99\%, 50nm) ${ }^{3}$.
All these methods have specific advantages and problems. The main advantages of carbothermic synthesis are the low cost of starting reagents, the usage of relatively easy equipment and the possibility to high-scale industrial application. The main disadvantage is requirement of many stages to precursors preparation. Metallothermic process has the same characteristics but it's products are typically contaminated by chemically inert metal borides. Plasma synthesis allows for large-scale production of high-dispersed, non-agglomerated powders of high purity, but it requires for expensive starting reagents, high energy consumption and rather complex equipment. The CVD method is typically used to obtain coatings and infiltrated composite bodies, and it has a small practical significance for nanopowders production because of expensive reagents, complexity of equipment and low production rates. Mechanochemical production requires specific milling parts made of superhard materials like sintered boron carbide. There is no possibility to obtain nanopowders with average particle size of tens nanometers. This method is only suitable for laboratory production of small quantities of powders.

In our opinion carbothermic synthesis can become the most suitable for large-scale production of $\mathrm{B}_{4} \mathrm{C}$ nanopowders at the nearby future.

\section{Boron carbide synthesis by carbothermic reduction}

Carbothermic reduction is the most widely used commercial production method for boron carbide. Inexpensive raw materials, relatively easy manufacturing process and scalability made carbothermic reduction suitable for large-scale commercial production of coarse-grained boron carbide. This method involves the reduction of boron-oxide with carbon in an electric arc furnace or resistive heating furnace (typically Acheson type) to produce boron carbide crystals. The basic reaction is shown below ${ }^{1}$ :

$$
2 \mathrm{~B}_{2} \mathrm{O}_{3}+7 \mathrm{C} \rightarrow \mathrm{B}_{4} \mathrm{C}+6 \mathrm{CO}
$$

This process takes place at the temperatures about $2500^{\circ} \mathrm{C}$, higher than melting point of $\mathrm{B}_{4} \mathrm{C}$. Such a temperature leads to formation of large boron carbide crystals containing difficultly removable 
impurities. For a long time, great efforts have been undertaken to achieve such characteristics of synthesis, like:

- $\quad$ Advance of product purity;

- $\quad$ Advance of product dispersity;

- Reduction of synthesis temperature;

- $\quad$ Search for ways of scale application in industry.

Unfortunately, simultaneous achieving all of characteristics mentioned above is inaccessible ideal until now.

The fact of special note is boron oxide is quite easily sublimates at the elevated temperatures (above $1300^{\circ} \mathrm{C}$ ). It leaves the reaction hot zone and collects in cooler zones of furnances. This results to deviations in stoichiometric composition of reaction mixture and final products. Scientists and technologists make required corrections in starting compositions ratios knowing about it ${ }^{1,4}$.

The scientists put out considerable effort in order to reduce the content of residual free carbon in the reaction mixtures after the carbothermic reduction of boric oxide. They used mainly two approaches: variation in the composition of precursors as well as an introduction of different additives to the precursors influencing the reaction mechanism. Most of synthetic routes are carried out with the temperature in range $1400-1600^{\circ} \mathrm{C}$ combining with vacuum or inert gas flow.

Thermodynamics and kinetics of carbothermic synthesis of boron carbide was also investigated $^{4,5}$.

The authors of paper ${ }^{6}$ conducted a study of the influence of heat treatment temperature and the starting composition of the reaction mixture on the morphology of the particles of boron carbide. The carbon black and boron oxide were used as starting materials. It is shown that the increase of synthesis temperature by and above $1550^{\circ} \mathrm{C}$ leads to an intense growth of the boron carbide crystals. Morphology of $\mathrm{B}_{4} \mathrm{C}$ particles synthesized at $1450^{\circ} \mathrm{C}$ was mainly spherical shapes. The $\mathrm{B}_{4} \mathrm{C}$ powder synthesized at $1550^{\circ} \mathrm{C}$ was large and changed in morphology from polyhedral to skeletal shape, and particle size of $\mathrm{B}_{4} \mathrm{C}$ increased with an increase in the amount of $\mathrm{B}_{2} \mathrm{O}_{3}$ in the starting mixtures. The $\mathrm{B}_{4} \mathrm{C}$ powder synthesized beyond $1650^{\circ} \mathrm{C}$ consisted from dendrite-like particles aggregated by small primary particles. Morphology of the primary $\mathrm{B}_{4} \mathrm{C}$ particles synthesized at $1750^{\circ} \mathrm{C}$ changed from polyhedral to rounded shape with increasing the amount of $\mathrm{B}_{2} \mathrm{O}_{3}$ in the starting mixtures.

The another paper of the same authors ${ }^{7}$ reviews the study of morphology control of boron carbide particles obtained under the influence of
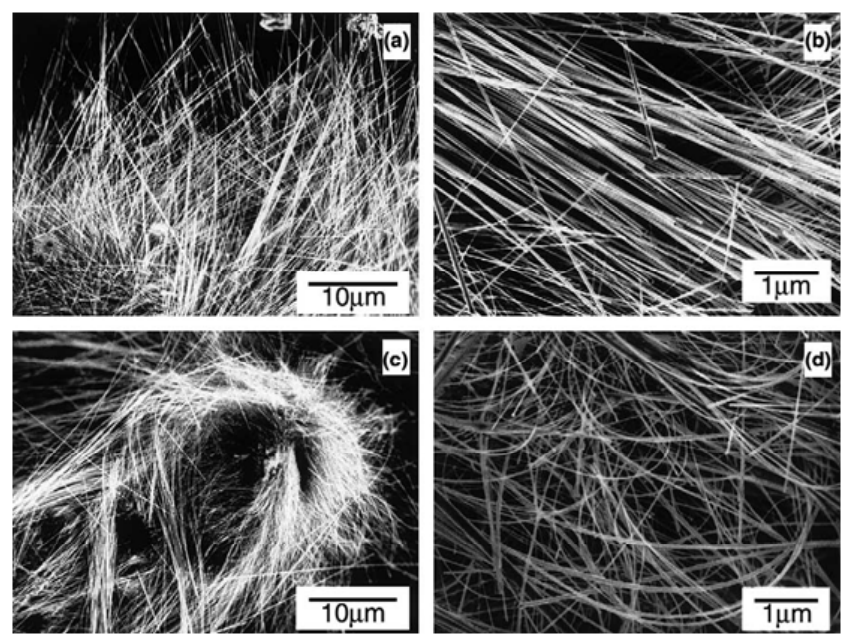

Fig. 2: SEM images of the deposit demonstrating dense nanowires.

The nanowires appear to grow both in long straight segments $(a, b)$ and in curly tufts (c, d) ${ }^{8}$. 
crystallizing nucleus, previously introduced into the reaction mixture. The carbon black and boron oxide were used as starting agents, and industrially produced boron carbide powders with different dispersion were used as crystallizing nuclei. The ratio of added $\mathrm{B}_{4} \mathrm{C}$-seed $/ \mathrm{B}_{2} \mathrm{O}_{3}$ was in the range of 0.01-0.2. The authors demonstrated that the introduction of boron carbide grains into the starting mixture increases the degree of conversion of the reaction mixture and reduces the content of free carbon, and improves the crystallinity of the product. As a result of the synthesis at temperatures $1450-1750^{\circ} \mathrm{C}$ boron carbide crystals were produced with different shape of facet pattern, which are formed due to the initial grain size growth. These crystals are also covered with a settling of nano-sized particles of indefinite shape. After synthesis at $1450^{\circ} \mathrm{C}$ for 3 hours in an argon flow, residual carbon and boron oxide were detected in the samples, during similar syntheses at temperatures $1550-1750^{\circ} \mathrm{C}$ residual carbon was detected only. The particle size of the resulting boron carbide decreased with an increase in the proportion of pre-introduced boron carbide particles.

Also, the possibility of obtaining singlecrystal nanofibers (nanowires) in the carbothermic production of boron carbide has been shown. For example, the authors of paper ${ }^{8}$ conducted high temperature vaporization of precursor B/ $\mathrm{B}_{2} \mathrm{O}_{3} / \mathrm{C}$ under argon atmosphere without the use of catalysts.

The method employed a mixed powder precursor containing boron powders, boron oxide powder and carbon black in the molar ratio of 2:1:1. The mixed $\mathrm{B} / \mathrm{B}_{2} \mathrm{O}_{3} / \mathrm{C}$ powder precursor was charged in the bottom of an open cylindrical graphite crucible (length $60 \mathrm{~mm}$, inner diameter $25 \mathrm{~mm}$ ) and itself inserted into a high frequency induction furnace. The furnace temperature was raised quickly to $1650^{\circ} \mathrm{C}$ within $15 \mathrm{~min}$ and held at this point for 2

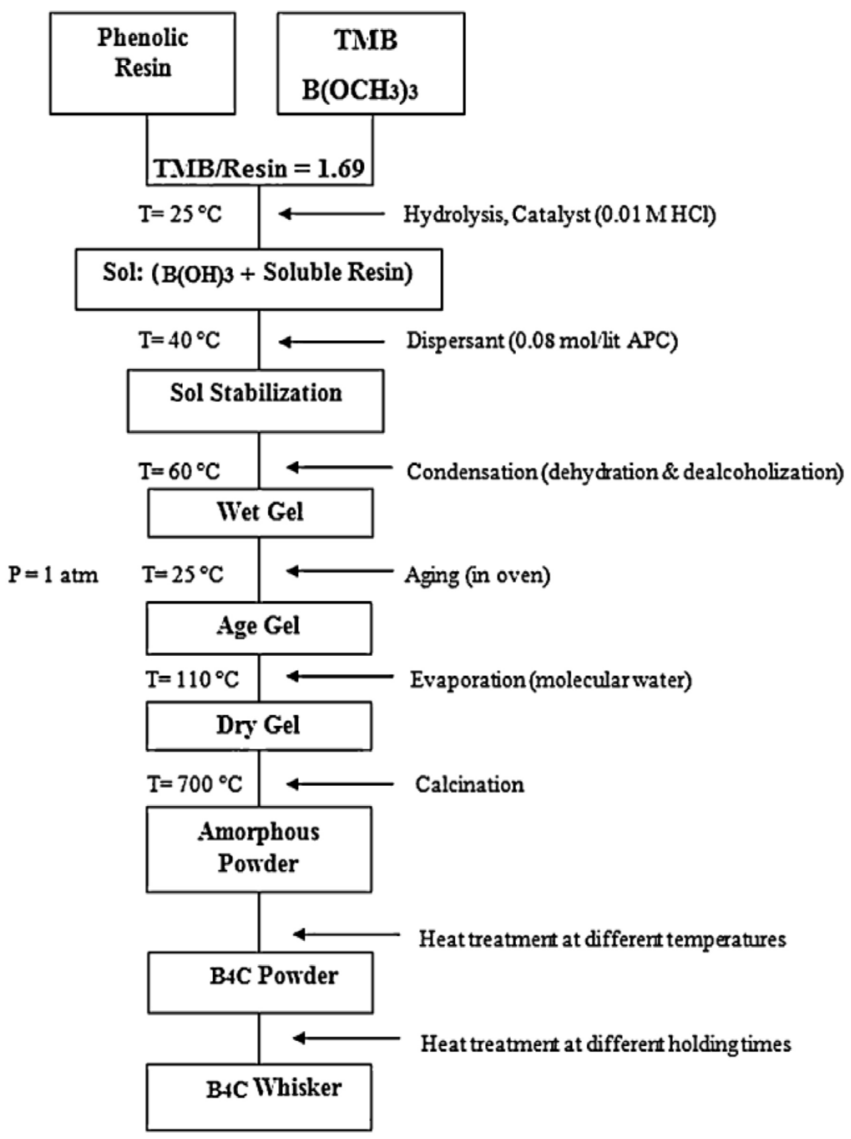

Fig. 3: Typical experimental scheme of B4C synthesis using sol-gel derived precursor ${ }^{14}$. 
h under flowing argon atmosphere (200 standard cubic centimeters per minute). After the evaporation, a grayish-black wool-like product deposited on the top wall of the crucible.

The resulting product has a thick needle structure with mean diameter of around $50 \mathrm{~nm}$ and with typical lengths of several tens to hundreds of micrometers (seeFig.2).

The mechanism of the growth of nanofibers proposed by the authors, involves the reaction of boron oxide vapor or boron monoxide dimer $\mathrm{B}_{2} \mathrm{O}_{2}$ (formed by reaction of boron oxide $\mathrm{B}_{2} \mathrm{O}_{3}$ with carbon) with carbon monoxide using the "vaporvapor" mechanism in slightly colder zone of the crucible. Presumably carbon dioxide is released as an additional reaction product.

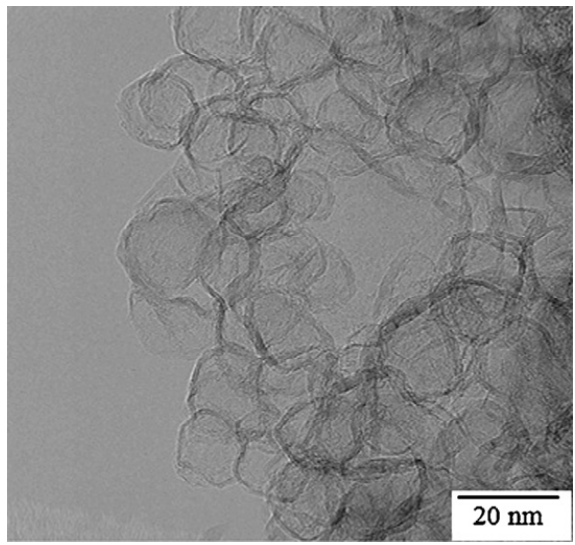

Fig. 4:TEM image of synthesized powder at $1270^{\circ} \mathrm{C}$ for $1 \mathrm{~h}^{14}$.
Authors 9 reported about $\mathrm{B}_{4} \mathrm{C}$ nanopowder synthesis using sucrose-boric acid precursor. The synthesis was carried out at the temperature range $1300-1500^{\circ} \mathrm{C}$. Agglomerates with wide-range particle distribution (from hundreds of nanometers to $20 \mu \mathrm{m}$ ) were received. The mean crystallite size calculated by Scherer method was $60 \mathrm{~nm}$.

Another method of producing a precursor for the synthesis of boron carbide was proposed in paper $^{10}$. The traditional boric acid was used as the boron source and 2-hydroxybenzyl alcohol $\left[\mathrm{C}_{6} \mathrm{H}_{4}\left(\mathrm{CH}_{2}-\mathrm{OH}\right)(\mathrm{OH}), \mathrm{HBA}\right]$ was used as the carbon source. These components were dissolved in DMF at $100^{\circ} \mathrm{C}$, and the esterification of boric acid and HBA occurred to form a polymer, such as phenolic resin. Boron carbide was prepared by single-stage heating the resulting polymer up to $1500^{\circ} \mathrm{C}$ under argon flow.

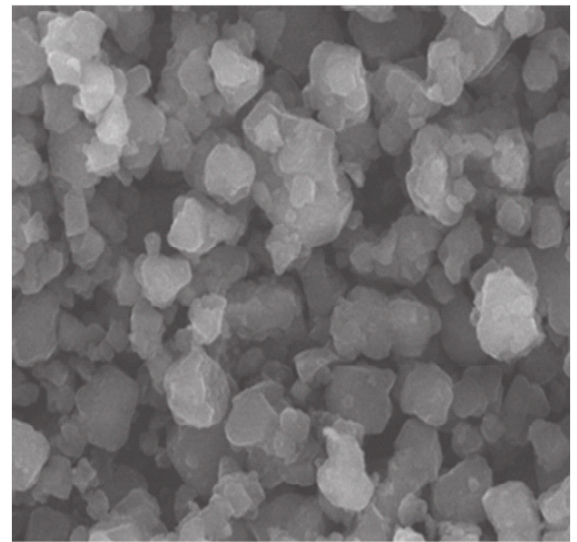

Fig. 5: SEM image of product obtained by heat treatment of TD-C21 at $1250{ }^{\circ} \mathrm{C}$ for $5 \mathrm{~h}$ in an $\mathrm{Ar}$ flow(the scale bar is $3 \mu \mathrm{m}$ ).
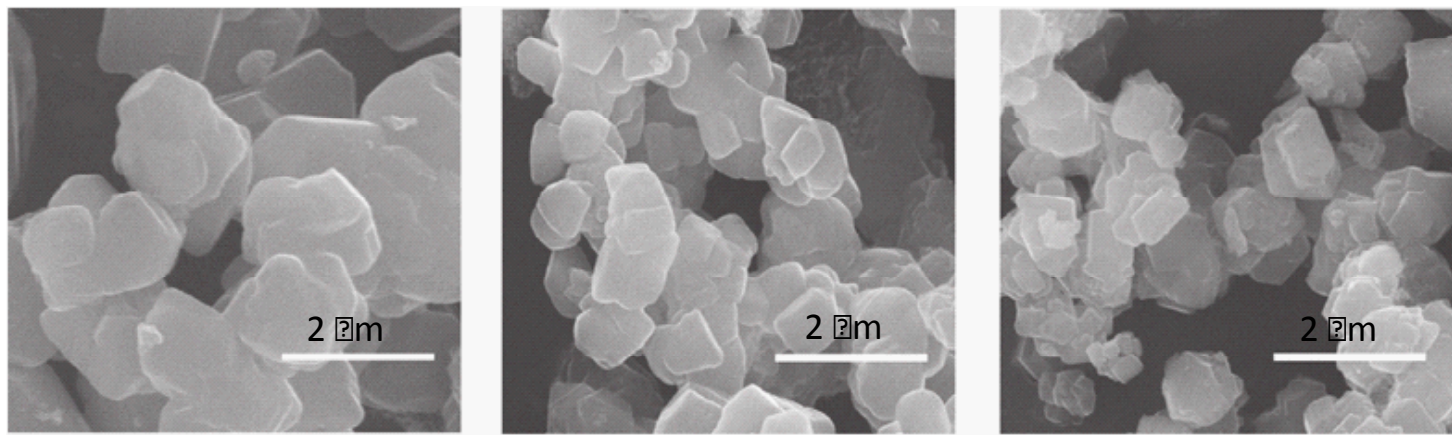

Fig. 6: SEM images of product powders obtained by heat treatment at $1250{ }^{\circ} \mathrm{C}$ for $5 \mathrm{~h}$ (left, center) and $1250{ }^{\circ} \mathrm{C}$ for $2 \mathrm{~h}$ in Ar flow (right) ${ }^{19}$. 
The article ${ }^{11}$ describes the influence of the introduction of ferric chloride and potassium carbonate. The carbon black and boron oxide are used as starting substances obtained from boric acid. These materials were exposed to the mixing in different proportions before heat treatment, followed by thorough grinding in an agate ball mill.

The formation of $\mathrm{B}_{4} \mathrm{C}$ through carbothermic reduction of $\mathrm{B}_{2} \mathrm{O}_{3}$ has been studied by varying boron to carbon molar ratio $(B: C=4: x)$ where $x=2.66 / 2.0 / 0.833$. The reaction was studied in a range of temperature of $1300-1625^{\circ} \mathrm{C}$ for $0.5 \mathrm{~h}$ in $1 \mathrm{~atm}$. argon. Residual free carbon was found with carbon content as low as 2.66 in the reaction mixture $(B: C=4: 2 \cdot 66)$. Potassium carbonate is used to produce low-melting boron-containing glassy phase. Addition of $\mathrm{K}_{2} \mathrm{CO}_{3}$ to reactant mixture has been found to decrease the free residual carbon. $\mathrm{B}_{2} \mathrm{O}_{3}$ has been found lost totally when the carbon content in the reactant mixture is very small ( $\mathrm{B}: \mathrm{C}=4: 0.833$ ). Addition of $\mathrm{FeCl}_{3}$ was found to decrease the loss of boric species by forming FeB, and to stabilize graphitic carbon. No peak, corresponding to free carbon was seen in $\mathrm{B}_{4} \mathrm{C}$ formed from reactant mixture containing boron and carbon in the ratio of $(B: C=4: 2)$. Large number of needles/platelets were formed with the addition of $\mathrm{FeCl}_{3} / \mathrm{K}_{2} \mathrm{CO}_{3}$.

Dispersity advancing often correlates with synthesis temperature decreasing. Starting precursors made by sol-gel method are typically used for low-temperature syntheses. Such precursors are made of low-molecularorganic compounds with hydroxyl or carboxyl groups serving as carbon source, and boric acid as boron source. Such techniques allow the closest contact and the most effective mixing of boron oxide and carbon particles during carbothermic reduction.

The group of authors synthesized nanoparticles ${ }^{12,13}$ and nanowhiskers ${ }^{14}$ of boron carbide, using phenolic resin and trimethylborate as the starting materials. It was prepared a multicomponent system of "water-solvent (DMF) - catalyst ( $\mathrm{HCl})$ - dispergator (ammonium polycarboxylate)" type. It was studied the effect of dwell time on the content of free carbon and morphology of boron carbide particles, obtained at $1270^{\circ} \mathrm{C}$. The experiment was conducted according to the scheme shown in Fig.3.

The authors suggest that the formation of boron carbide $\mathrm{B}_{4} \mathrm{C}$ occurs at elevated temperatures in complex multi-stage reactions, while the equations of prevailing elementary reactions have the following form:

$$
\begin{gathered}
\mathrm{B}_{2} \mathrm{O}_{3(\mathrm{l})}+\mathrm{C}_{(\mathrm{s})} \rightarrow \mathrm{B}_{2} \mathrm{O}_{2(\mathrm{~g})}+\mathrm{CO} \\
2 \mathrm{~B}_{2} \mathrm{O}_{2(\mathrm{~g})}+5 \mathrm{C}_{(\mathrm{s})} \rightarrow \mathrm{B}_{4} \mathrm{C}_{(\mathrm{s})}+4 \mathrm{CO}_{(\mathrm{g})}
\end{gathered}
$$

During the high temperature stage of the synthesis, which was carried out at a temperature of $1270^{\circ} \mathrm{C}$ with dwell time for 1 hour, the authors of this paper obtained the particles with the shape that was close to spherical. Estimated average crystallite size was $12.2 \mathrm{~nm}$. With increasing exposure to 3 hours, the average crystallite size also increased and amounted to $17.6 \mathrm{~nm}$. According to the data from transmission electron microscopy (TEM) the particles had a round shape and their diameter reached 10-30 nm (1 hour), 20-40 nm (2 hours), and finally, in samples exposed for 3 hours, the elongated nanocrystals of boron carbide formed with averazge diameter of 20-40 nm (see Fig.4).

The obtaining of high quality $\mathrm{B}_{4} \mathrm{C}$ nanopowders was carried out using D-mannitolboric acid precursor ${ }^{15}$. This precursor was dried, carbonized and after that heated up to $1100-1300^{\circ} \mathrm{C}$ at $0,5-20 \mathrm{~h}$. The formation of boron carbide was observed at temperatures $1150^{\circ} \mathrm{C}$ and higher. Besides in those experiments minimal free carbon content was achieved (less than 1\%). Average agglomerate size was $0.5-1 \mu \mathrm{m}$ (see Fig.5).

The same results were obtained by different research groups. For instance, boron carbide powders were obtained on the base of boric acid-citric acid condensation products $[16,17]$ and glycerol $^{18,19}$ (see Fig.6).

Rapid carbothermic reduction technique was invented ${ }^{20,21}$. This method involves rapid heating to the high temperatures (about $2000 \mathrm{~K}$ ) and small exposition time (up to ten minutes). This allows to avoid agglomeration of powders. Microwave irradiation may be used for heating intensification. 


\section{CONCLUSION}

This review shows different approaches to carbothermic synthesis of nanosized and submicron boron carbide, main factors and correlations influencing the process. Now there are a lot of successful laboratory research works. Scientists are able to obtain highly dispersed $\mathrm{B}_{4} \mathrm{C}$ powders of high purity and of different particle size. The nanostructured forms of carbon or low-molecular organic compounds containing many hydroxyl and carboxyl groups are used as carbon source in reaction mixtures. The boric acid or it's ethers are used as boron source. The purest $\mathrm{B}_{4} \mathrm{C}$ powders obtained by carbothermic reduction contains less than one percent of free carbon without additional purification.
The correct selection and processing of precursors allows to reduce the synthesis temperature to 1200 $1300^{\circ} \mathrm{C}$. The carbothermic reduction is useful method for future industry application. In the nearby future nanosized and submicron boron carbide powders will become widely available, and this fact will open new possibilities for materials science and engineering.

\section{ACKNOWLEDGEMENTS}

Applied researches are carried out with state financial support represented by the Ministry of Education of Russia under the Agreement on granting subsidies No.14.625.21.0035 of October 27, 2015. (Unique identifier of Applied Scientific Researches (project) RFMEFI62515X0035).

\section{REFERENCES}

1. Toksoy, M.F. A Dissertation submitted to the Graduate School-New Brunswick. Rutgers, The State University of New Jersey in partial fulfillment of the requirements for the degree of Doctor of Philosophy, Graduate Program in Materials Science and Engineering. New Brunswick, New Jersey, 2014.

2. Suri, A.K.; Krishnamurthy, N.; Subramanian, C. Advanced Processing and Manufacturing Technologies for Structural and Multifunctional Materials III, 69-79.

3. URL: http://www.ssnano.com/inc/sdetail/ boron_carbide_nanoparticles/290

4. Weimer, A.W.; Moore, W.G.; Roach, R.; Hitt, J.E.; Dixit, R.S.; Pratsinis, S.E. J. Am. Ceram. Soc. 1992, 75, 2509-2514.

5. Dacic, B.Z.; Jokanovi, V.; Jokanovi, B.; Drami anin, M.D. Journal of Alloys and Compounds 2006, 413, 198-205.

6. Kobayashi, T; Yoshida, K.; Yano, T. Ceramics International 2013, 39, 597-603.

7. Kobayashi, T; Yoshida, K.; Yano, T. Ceramics International 2013, 39, 3849-3856.

8. Ma, R.; Bando, Y. Chemical Physics Letters 2002, 364, 314-317.

9. Trinadha Raja Pilladi; Ananthansivan, K.; Anthonysamy, S. Powder Technology 2013, 246, 247-251.

10. Hasegawa, I.; Fujii, Y.; Takayama, T.; Yamada, K. Journal of Materials Science Letters 1999,
$18,1629-1631$.

11. Krishnarao, R.V.; Subrahmanyam, J.; Jagadish Kumar, T.; Ramakrishna, V. Journal of Alloys and Compounds 2010, 496, 572-576.

12. Najafi, A.; Golestani-Fard, F.; Rezaie, H.R.; Ehsani, N. Ceramics International 2012, 38, 3583-3589.

13. Najafi, A.; Golestani-Farda, F.; Rezaiea, H.R.; Ehsani, N. Journal of Alloys and Compounds 2011, 509, 9164-9170.

14. Farzaneha, F.; Golestanifarda, F.; Sheikhaleslamia, M. Sh.; Nourbakhshb, A.A. Ceramics International 2015, 41, 10, A, 13658-13662.

15. Kakiage, M.; Tominaga, Y.; Yanase, I.; Kobayashi, H. Powder Technology 2012, 221, 257-263.

16. A.M. Hadian and J.A. Bigdeloo. Journal of Materials Engineering and Performance 2008, 17 (1), 44-49.

17. Khanara, A.K. Bull. Mater. Sci., 2007, 30, 2, 93-96.

18. Wada, H.; Ito, S.; Kuroda, K.; Kato, C. Chemistry Letters 1985, 14, 691-692.

19. Tahara, N.; Kakiage, M.; Yanase, I.; Kobayashi, $\mathrm{H}$. Journal of Alloys and Compounds 2013, 573, 58-64.

20. Weimer, A.W.; Roach, R.P.; Haney, C.N.; Moore, W.G.; Rafaniello, W. AIChE Journal, 1991, 37 (5), 759-768. 
21. Gao, Y.; Etzold, A.; Munhollon, T.; Rafaniello, W.; Haber, R. Diamond \& Related Materials 2016, 61, 14-20.

22. Singh, P.; Singh, B.; Kumar, M.; Kumar, A. Ceramics International 2014, 40, 1533115334.

23. Shi, L.; Gu, Y.; Chen, L.; Qian, Y.; Yang, Z.; Ma, J. Solid State Communications 2003, 128, 5-7.

24. Forouzan, M.R.; Taherzadeh Mousavian, R.; Sharif, T.; Afkham, Y.A. J. Therm. Anal. Calorim. 2015, 122, 579-588.

25. Ponomarev V. I.; Kovalev, I. D.; Vershinnikov, V. I.; Kovalev, D. Yu.; Konovalikhin, S. V. International Journal of Self-Propagating High-Temperature Synthesis 2015, 24 (4), 216-219.

26. Du, S.W.; Ling Yoong Tok, A.; Boey, F.Y.C. Solid State Phenomena 2008, 136, 23-38.
27. Mishra, A.; Sahoo, R.K.; Singh, S.K.; Mishra, B.K. Journal of Asian Ceramic Societies 2015, 3 (4), 373-376.

28. Sivkov, A.A.; Rakhmatullin, I.A.; Makarova, A.F. Nanotechnologies in Russia 2014, 9, 674-681.

29. Oliveira, J.C.; Conde, O. Thin Solid Films 1997, 307, 1, 29-37.

30. Koumoto, K.; Seki, K.; Seki, T.; Pai, Ch.H.; Yanagida, H. Journal of the Ceramic Society of Japan 1992, 100 (1162), 853-857.

31. Mohammad Sharifi, E.; Karimzadeh, F.; Enayati, M.H. Advanced Powder Technology 2011, 22 (3), 354-358.

32. Deng, F.; Xie, H.-Y.; Wang, L. Materials Letters 2006, 60, 13-14, 1771-1773.

33. Ramos, A.S.; Taguchi, S.P.; Ramos, E.C.T.; Arantes, V.L.; Ribeiro, S. Materials Science and Engineering A 2006, 422, 184-188. 